
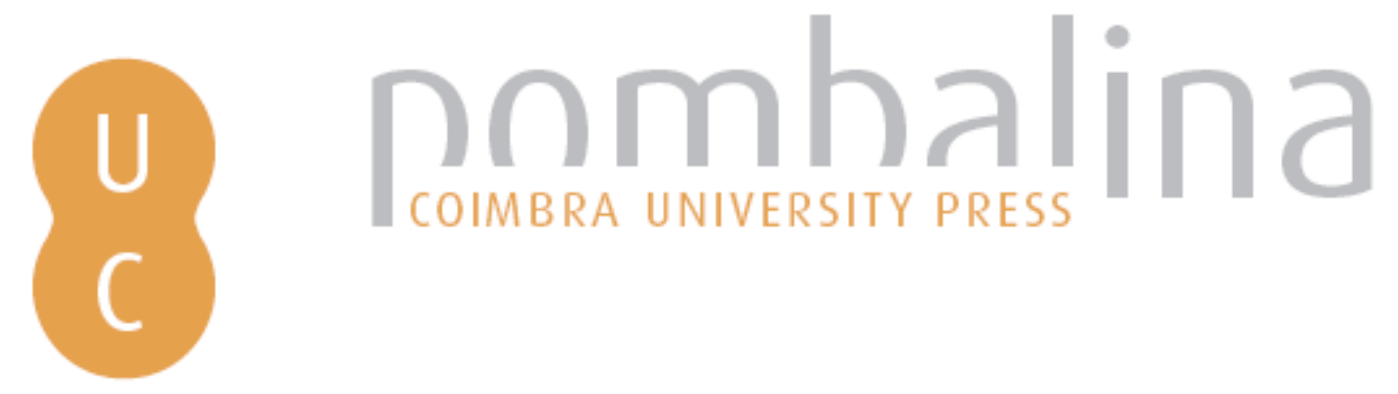

\title{
Sistemas de informação geográfica no suporte à gestão municipal: estudo comparativo dos casos de Joinville (SC,Brasil) e Amadora (AML, Portugal)
}

Autor(es): $\quad$ Julião, Rui Pedro; Loch, Carlos; Rosenfeldt, Yuzi

Publicado por: Imprensa da Universidade de Coimbra

URL

persistente: URI:http://hdl.handle.net/10316.2/37086

DOI: $\quad$ DOI:http://dx.doi.org/10.14195/978-989-26-0983-6_34

Accessed : $\quad$ 26-Apr-2023 12:40:35

A navegação consulta e descarregamento dos títulos inseridos nas Bibliotecas Digitais UC Digitalis, UC Pombalina e UC Impactum, pressupõem a aceitação plena e sem reservas dos Termos e Condições de Uso destas Bibliotecas Digitais, disponíveis em https://digitalis.uc.pt/pt-pt/termos.

Conforme exposto nos referidos Termos e Condições de Uso, o descarregamento de títulos de acesso restrito requer uma licença válida de autorização devendo o utilizador aceder ao(s) documento(s) a partir de um endereço de IP da instituição detentora da supramencionada licença.

Ao utilizador é apenas permitido o descarregamento para uso pessoal, pelo que o emprego do(s) título(s) descarregado(s) para outro fim, designadamente comercial, carece de autorização do respetivo autor ou editor da obra.

Na medida em que todas as obras da UC Digitalis se encontram protegidas pelo Código do Direito de Autor e Direitos Conexos e demais legislação aplicável, toda a cópia, parcial ou total, deste documento, nos casos em que é legalmente admitida, deverá conter ou fazer-se acompanhar por este aviso.

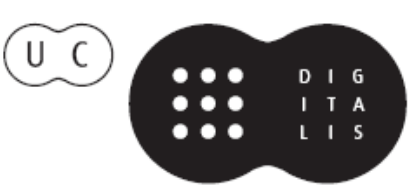




\section{$\forall$ \\ TAS DAS I JORNADAS LUSÓFONAS DE CIÊNCIAS E TECNOLOGIAS DE INFORMAÇÃO GEOGRÁFICA}

Editores

José Gomes dos Santos

Cidália Fonte

Rui Ferreira de Figueiredo

Alberto Cardoso

Gil Gonçalves

José Paulo Almeida

Sara Baptista 


\section{ARTIGO 34}

\section{SISTEMAS DE INFORMAÇÃo GEOGRÁfiCA NO SUPORTE À GESTÃO MUNICIPAL - ESTUDO COMPARATIVO DOS CASOS DE JOINVille, SC (BRASil) E AMAdora, AML (PORTUGAL)} JULIÃO, Rui Pedro ${ }^{1}$; LOCH, Carlos $^{2}$ E ROSENFELDT, Yuzi

\footnotetext{
1e-GEO-FCSH/UNL (Portugal); Avenida de Berna, 26-C 1069-061 Lisboa, Portugal; Tel: +351217908 300; email: rpj@fcsh.unl.pt

2, 3 Universidade Federal de Santa Catarina - UFSC (Brasil); Laboratório de Fotogrametria, Sensoriamento Remoto e Geoprocessamento (LabFSG); Rua João Pio Duarte Silva, s/n, Campus Universitário, Córrego Grande; Florianópolis, SC - CEP 88040-970; Caixa Postal 176, Brasil; Tel: +55 (48) 3721-7049; email: 2carlos.loch@ufsc.br; 3 arquitetayuzi@yahoo.com.br
}

\section{RESUMO}

A dinâmica demográfica e urbana dos grandes centros urbanos sofreu nos últimos 50 anos uma forte acentuação, por via de crescimento natural, mas sobretudo por via de migrações (internas e externas). Como resultado, a pressão sobre o território das áreas mais atrativas atingiu níveis críticos e geraram-se fenómenos de ocupação irregular do espaço, muitas vezes sem a garantia das condições mínimas de habitabilidade e sem o necessário respeito pelas condições ambientais.

A atuação das entidades públicas tem de se suportar num conhecimento seguro e atualizado da realidade, bem como na correta utilização de tecnologias que lhes permitam avaliar e perspetivar as medidas a adotar.

Este artigo efetua uma discussão comparada entre dois casos de estudo (Joinville, SC - Brasil e Amadora, AML - Portugal), colocando em evidência o uso das Tecnologias de Informação 
Geográfica (TIG) pelas Câmaras Municipais e a importância do cadastro, por forma a extrapolar linhas de orientação para outras situações similares existentes nestes e noutros países.

\section{PALAVRAS-CHAVE}

Tecnologias de informação geográfica, Cadastro técnico multifinaliltário, Regularização fundiária, Favelas, AUGI.

\section{GIS SUPPORT IN MUNICIPAL MANAGEMENT - A COMPARATIVE STUDY BETWEEN AMAdORA (AML, PORTUGAL) AND JOINVILLE（SC，BRASIL）CASE STUDIESABSTRACT}

The demographic and urban dynamics of large urban centres had a strong increase in the last 50 years, through natural growth, but even more through migration (internal and external). As a result, the pressure over territory on the most attractive areas reached critical levels and generated phenomena of irregular occupation of space, often without the guarantee of minimum living conditions and without complying with environmental conditions The action of public authorities must be supported by a safe and updated knowledge of reality as well as the correct use of technologies that enable them to assess and foresee measures to be adopted.

This article makes a comparative discussion of two case studies (Joinville , SC - Brazil and Amadora, AML - Portugal), highlighting the use of Geographic Information Technologies (GIT) by local municipalities and the importance of cadastre in order to extrapolate guidelines for other similar situations existing in these and other countries.

\section{KEYWORDS}

Geographic information technologies, Multipurpose technical cadastre, Land administration, Slum areas, AUGI.

\section{INTRODUÇÃO}

A dinâmica demográfica e urbana dos grandes centros urbanos sofreu nos últimos 50 anos uma forte acentuação, por via de crescimento natural, mas sobretudo por via de migrações (internas e externas). Como resultado, a pressão sobre o território das áreas mais atractivas atingiu níveis críticos e geraram-se fenómenos de ocupação irregular do espaço, muitas vezes sem a garantia das condições mínimas de habitabilidade e sem o necessário respeito pelas condições ambientais. Consequentemente, 
foram produzidos territórios "insustentáveis" (entre aspas, dada a prevalência e mesmo crescimento de alguns deles ao longo dos últimos anos) do ponto de vista físico, humano e social.

A Organização das Nações Unidas (ONU) estima que cerca de 50\% da população habite em áreas urbanas, com uma previsão na ordem dos $70 \%$ para 2020 , sendo que um terço o faz em áreas sem condições, designadas em língua Portuguesa por favelas, bairros de lata, musseques ou caniços. Chama também a atenção para a necessidade de analisar de forma cuidada e prospetiva a situação referindo que "Cities must create the conditions (and record accurate data) that will enable them to understand and anticipate trends, including the growth or decline of some areas or regions, if they are to be in a position to develop expansionary or recovery strategies" (UN-HABITAT, 2012: 26).

Conscientes destas realidades, foram muitos os governos que instituíram políticas de reordenamento territorial e regularização fundiária, no sentido de contribuir para a reconversão das áreas abrangidas por ocupações inadequadas e em condições precárias de habitação, por forma a viabilizar a sua requalificação (caso seja viável) e melhorar as condições de vida das populações que nelas residem. O Brasil e Portugal, não foram exceção e são bons exemplos destas iniciativas. Todavia, a capacidade de atuação por parte dos agentes públicos carece da existência de dados consolidados sobre a realidade e do emprego de instrumentos adequados à sua exploração.

No contexto brasileiro é fundamental contribuir para o aperfeiçoamento dos Programas de Urbanização de Assentamentos Precários e da Política Habitacional. É nesse sentido que há um projecto em execução pela Universidade Federal de Santa Catarina e que tem por principal objetivo desenvolver e consolidar uma metodologia de monitoramento e avaliação da relação entre a ocupação antrópica, meio ambiente e paisagem nos projetos de urbanização de assentamentos precários do Programa de Aceleração do Crescimento (PAC). Este projecto tem vários casos de estudo, entre eles, o do município de Joinville, SC (Brasil).

A experiência do contexto português, exemplificada pelo trabalho 
desenvolvido no município da Amadora, permitiu ter uma base comparativa (por vezes muito semelhante) e assim corroborar as definições metodológicas do caso brasileiro de Joinville, SC.

Este artigo efetua assim uma discussão comparada entre dois casos de estudo (Joinville, SC - Brasil e Amadora, AML - Portugal), colocando em evidência o uso das Tecnologias de Informação Geográfica (TIG) nos municípios, dando maior relevo às suas componentes de visualização e consulta de dados geográficos (sendo certo que há muitas outras, designadamente as suportadas por processos de análise espacial e que suportam a tomada de decisão por partes dos erviços e executivos municipais) e também a importância do cadastro predial (cadastro técnico multifinalitário, como é conhecido no Brasil), por forma a extrapolar linhas de orientação para outras situações similares existentes nestes e noutros países do espaço lusófono.

\section{CASO DE ESTUdO: JOINVILLE, SC (BRASIL)}

A atual situação das favelas brasileiras é bem conhecida do mundo inteiro e trata-se de um problema de grande dimensão e complexidade, com óbvios reflexos no quotidiano das cidades.

A origem da designação informal de "Favela" remonta a finais do século XIX, início do século XX. Na época, com a publicação da Lei Aúrea em 1888, foi dada liberdade aos escravos e isso acabou por motivar a saída desta população das fazendas, o que conjugado com a reforma urbana do Rio de Janeiro em 1904, levou à ocupação dos morros. Entre eles o Morro da Favela. Daí a designação que ainda hoje prevalece.

O Instituto Brasileiro de Geografia e Estatística (IBGE), de acordo com os dados do Censos de 2010, estima que haja mais de 11 milhões de habitantes distribuídos por mais de 6000 aglomerados subnormais (designação oficial para favela).

Numa perspetiva mais local, o Estado de Santa Catarina, embora com uma expressão menor (cerca de 75 mil habitantes a residir em favelas, segundo os dados do IBGE), também tem áreas onde esta tipologia de ocupação urbana se manifesta. As cidades com maior número de habitantes 
a residir em favelas são Blumenau com 22363 habitantes e Florianópolis, capital do estado, com 17543 habitantes.

Já em Joinville, cidade predominantemente ligada à actividade industrial do norte do Estado de Santa Catarina, que tem uma população global na ordem dos 500000 habitantes, há duas tipologias completamente distintas de produção irregular de espaço urbano:

- Aglomerados subnormais (favelas) com ocupação de terrenos, na sua maioria públicos

- Aglomerados ilegais resultantes do fraccionamento irregular da propriedade e/ou construção não licenciada.

Nesta cidade o fenómeno das favelas não tem grande expressão espacial e quantitativa (cerca de 7000 habitantes), sendo substancialmente superior a segunda tipologia de produção irregular de espaço urbano.

A Prefeitura de Joinville tem promovido a incorporação das tecnologias de informação geográfica no seu funcionamento quotidiano, através da Fundação Instituto de Pesquisa e Planejamento para o Desenvolvimento Sustentável de Joinville (IPPUJ).

\subsection{Procedimentos metodológicos e resultados}

Os principais resultados de todo este investimento, em tecnologias de informação geográfica e na reorganização funcional das estruturas orgânicas do município, viabilizaram a criação de um eficaz suporte do sistema de planeamento, materializado através de várias camadas aplicacionais integradas no Sistema de Informação Geográfica (SIG) de Joinville (http://geoprocessamento.joinville.sc.gov.br/).

O SIMGeo concebido e desenvolvido pelo IPPUJ tem três componentes principais:

- SIMGeo Joinville

- SIMGeo Downloads

- SIMGeo Joinville + (não disponível para o exterior)

O SIMGeo Joinville é a base de exploração, aberta ao público em geral, que funciona como verdadeiro portal de acesso ao SIG municipal, desig- 
nadamente às camadas de dados de interesse geral: Divisão Territorial, Planeamento, Património Histórico-Cultural, Turismo, Educação, Saúde, Meio Ambiente, Assistência Social e Defesa Civil.

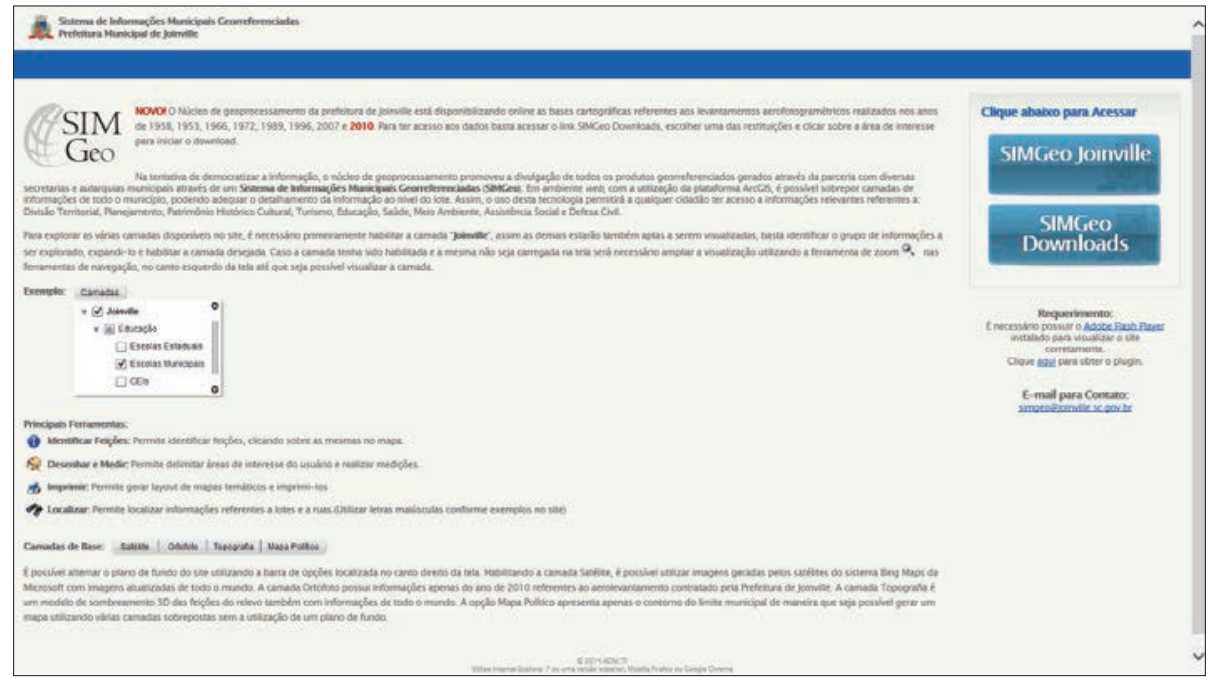

Figura 1 - Geoportal de Joinville

Em termos de informação de contexto é possível ativar o limite administrativo do município, os ortofotomapas do último voo de 2010 (embora a resolução destes esteja degrada para otimizar a rapidez de refrescamento dos conteúdos), ou a topografia e as imagens de satélite do Bing Maps.

Todas estas camadas de informações podem ser sobrepostas a uma base de informação cadastral com detalhamento da informação ao nível do lote, criando assim uma excelente base de informação municipal.

Cada um dos lotes está codificado de forma unívoca recorrendo a um sistema de 5 blocos de dígitos que correspondem a: Quadrante, Quadrícula, Setor, Quadra e Lote.

Para efeitos de exploração dos dados cadastrais (não disponibilizados ao público por questões de protecção de dados pessoais), cada lote subdivide-se ainda nas suas diferentes unidades autónomas, decompondo-se estas em várias unidades de avaliação.

Está assim garantido de forma simples e acessível a total integração da informação do particular para o geral e vice-versa, com a possibili- 
dade de gerar indicadores relevantes para a monitorização do território.

O SIGGeo Downloads é uma componente que permite efetuar o descarregamento do acervo histórico de coberturas aerofotográficas e/ou respectivas restituições de Joinville:

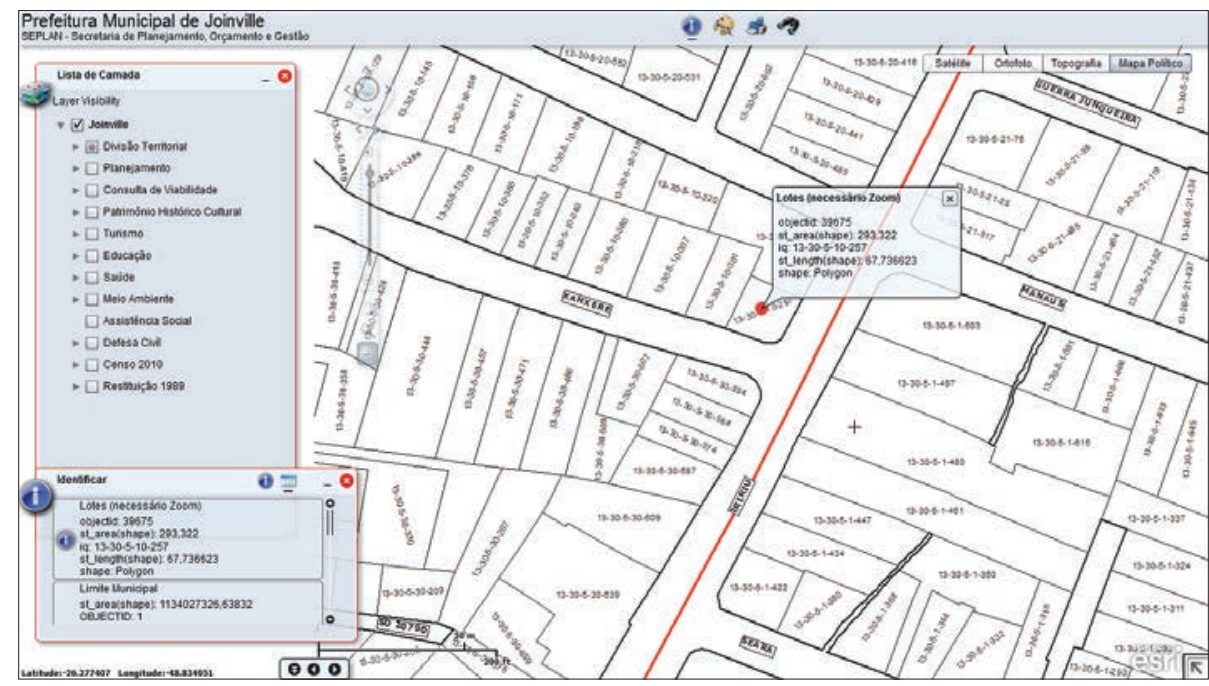

Figura 2 - SIMGeo Joinville: consulta de lote

- Cobertura Aerofotogramétrica de 1938

- Cobertura Aerofotogramétrica de 1953

- Cobertura Aerofotogramétrica de 1966

- Cobertura Aerofotogramétrica de 1972

- Restituição Aerofotogramétrica de 1989

- Cobertura Aerofotogramétrica de 1996

- Restituição Aerofotogramétrica de 2007

- Restituição Aerofotogramétrica de 2010

Esta componente viabilizou o acesso à informação por parte dos utilizadores externos, garantindo em simultâneo a libertação do afluxo de pedidos aos serviços do município e a receção de dados em melhores condições de georreferenciamento. Todavia, o município reconhece que ainda ocorrem problemas pelo fato deste ter adotado o sistema SIRGAS 2000 (Sistema de Referência Geocêntrico para as Américas, equivalente 
ao ETRS 89 da Europa) que ainda não é plenamente dominado por todos os técnicos da área da topografia.

Por fim o SIMGeo + é a plataforma de acesso restrito (não está aberta ao exterior e só o executivo municipal tem acesso) onde se pode ter acesso a dados de interesse para a gestão executiva do município. Esta ferramenta integra, para além dos elementos do SIMGeo Joinville uma série de informações georreferenciadas sobre elementos estratégicos do município (propostas de zonamento, estudos e projectos), intervenções dos serviços (por realizar, em curso e sua monitorização) e suporta o funcionamento das reuniões do executivo municipal.

Para além do SIMGeo existe ainda uma outra aplicação, o Sistema de Gestão Cadastral (SGC) que caracteriza ao detalhe, para efeitos de cálculo de imposto, todas os lotes. Estes dados estão compilados no boletim de informação cadastral que existe para todas as unidades autónomas, mesmo para os lotes de uso rural, pois o município de Joinville fez o seu levantamento (geométrico e de atributos) e substitui-se hoje à Receita Federal na gestão e cobrança do Imposto sobre a Propriedade Territorial Rural (ITR).

Para além das aplicações imediatas no âmbito do ITR e do Imposto Predial Territorial Urbano (IPTU), o conjunto de dados do SGC é de extrema relevância para as atuações em termos de ordenamento e gestão urbanística. Confere a possibilidade de efectuar a identificação, localização e desenho inequívoco das áreas objecto das operações, bem como identificar os seus proprietários. Suporta igualmente os estudos de caracterização do território do município em termos das suas características de uso e ocupação, tipologia do edificado, materiais de construção, etc.

\section{CASo de estudo: Amadora, AmL (Portugal)}

Em Portugal, desde o final dos anos 50-60, começaram a verificar-se fortes fluxos migratórios internos e externos, sendo a Área Metropolitana de Lisboa um dos pólos que maior crescimento de população registou. Este fenómeno sofreu uma acentuada escalada após o 25 de Abril de 1974, sobretudo quando se registou o retorno das populações que ha- 
bitavam nos até então territórios ultramarinos de Portugal (RAPOSO \& VALENTE, 2010).

Consequentemente e com um expressivo significado territorial, também por via da influência do movimento revolucionário, desenvolveram-se vários núcleos de habitação fora dos trâmites formais de licenciamento, resultando em áreas subequipadas, mal infraestruradas e, por vezes, com habitação precária e/ou degradada. Foi a conhecida expansão do fenómeno dos Bairros de Lata e de Clandestinos.

Consciente da insustentabilidade da produção de território urbano irregular e das consequências negativas (físicas, sanitárias e sociais) que a mesma acarreta, os governos lançaram várias iniciativas para suster e inverter o processo. O Decreto-Lei n. ${ }^{\circ}$ 163/93, de 7 de maio, vem criar o Programa Especial de Realojamento (PER) nas Áreas Metropolitanas de Lisboa e do Porto e a Lei n. ${ }^{\circ}$ 91/95, de 2 de Setembro, vem lançar o processo de reconversão das Áreas Urbanas de Génese Ilegal, hoje vulgarmente conhecidas por AUGI.

O município da Amadora (criado apenas em 1979 por desagregação do município de Oeiras) não foi execeção. "Na década de 70, as correntes migratórias intensificaram-se e diversificaram-se" (CESIS, 2004: 22). Este município sofreu assim um forte acréscimo populacional nos últimos anos do século passado (mais do que triplicou a população), tendo depois estagnado. Hoje, este município, adjacente a Lisboa e o mais pequeno da AML (com 24km2), apresenta a mais elevada densidade populacional do país (7 363,4 hab/km2), fruto dos seus cerca de 175 mil habitantes.

O fenómeno da habitação degrada é bem conhecido e tem sido trabalhado pelo município nos últimos anos com várias iniciativas de realojamento e de reconversão das AUGI.

\subsection{Procedimentos metodológicos e resultados}

Uma das principais dificuldades sentidas pelas câmaras municipais está relacionada com a dinâmica de transformação do território que compromete a actualização dos dados existentes nos SIG municipais. Cardoso (2011) propôs uma estrutura de modelo de dados municipal que contemplava a 
articulação de quatro domínios chave da atuação municipal (Território, Ordenamento, Licenciamento e Fiscalização) e Pinto (2011) uma abordagem metodológica para a integração de dados da gestão quotidiana na cartografia municipal. São dois bons exemplos de soluções para estruturar e agilizar a produção e actualização da informação geográfica municipal.

A Câmara Municipal da Amadora (CMA) tem vindo a desenvolver a implementação do seu Sistema de Informação Geográfica (SIG), da mesma forma que os restantes municípios portugueses que apresentam já um elevado nível de adopção dos SIG (JULIÃO et al, 2009) e a colocar em prática uma série de procedimentos que garantam a eficaz produção e actualização dos dados que constam das suas bases geográficas.

Nesse sentido, a sua estrutura orgânica, suportada pelo Despacho n. ${ }^{\circ}$ 882/2013, publicado no Diário da República 2. ${ }^{a}$ série - n. ${ }^{\circ} 11$ a 16 de janeiro de 2013, contempla a Divisão de Informação Geográfica (DIG) como unidade da estrutura flexível da CMA e diretamente dependente do Presidente da Câmara. Entre as suas várias competências, destacam-se as de (extraído do despacho acima referido):

a) Conceber, gerir e manter a infraestrutura de dados espaciais (IDE) do município da Amadora;

e) Colaborar com a unidade orgânica competente na conceção e implementação de serviços internos de informação geográfica de apoio ao licenciamento manter atualizadas as bases espaciais de operações urbanísticas e definir os requisitos técnicos a que deverão obedecer os projetos de loteamento e de obras particulares para incorporação na infraestrutura de dados espaciais;

h) Definir os modelos de dados de informação geográfica municipal;

i) Adquirir e manter bases cartográficas homologadas, pela respetiva autoridade nacional, cumprindo a legislação específica de cartografia e o quadro legal que regula a elaboração de Planos Municipais de Ordenamento do Território;

j) Produzir e manter a cartografia de referência e temática de apoio ao 
ordenamento do território e atividade municipal;

1) Promover a execução de levantamentos topográficos junto da unidade orgânica competente e reforçar a complementaridade deste serviço nos projetos de cadastro predial: SINERGIC, Sistema Nacional de Exploração e Gestão de Informação Cadastral.

Este despacho prevê ainda a obrigação de outras unidades funcionais do município se articularem com a DIG na sua atuação. Por exemplo, de acordo com a alínea e) do n. 3 do artigo $14^{\circ}$, o Departamento de Administração Urbanística tem de "solicitar à Divisão de Informação Geográfica os pareceres sobre cadastro quando os processos se situem em zona sem urbanização definida”.

Está assim reconhecida a importância da informação geográfica e criadas as bases de organização interna que reforçam a correta utilização e actualização da base de conteúdos geográficos para suportar o bom desempenho dos serviços municipais.

No plano operacional a equipa do SIG da CMA tem procurado adequar os conteúdos e as tecnologia adotadas ao longo da sua existência. Desde o nascimento do projecto em 2003, foram várias as iniciativas que permitiram consolidar o SIG e dotá-lo dos conteúdos e das funcionalidades fundamentais para o suporte ao funcionamento dos serviços municipais (SILVA, 2010). Destaca-se a cartografia em base de dados com toponímia e números de polícia, a georreferenciação dos equipamentos, a emissão de plantas de localização, o webgis (hoje geoportal) e o lançamento de uma infraestrutura de dados espaciais local.

Com efeito, a Diretiva INSPIRE (transposta para a legislação nacional através do Decreto-Lei n. ${ }^{\circ}$ 180/2009, de 7 de agosto), concretiza que um Geoportal é um "sítio de Internet que dá acesso aos serviços de dados geográficos das autoridades públicas”.

Nesse sentido, o Município da Amadora disponibiliza o Geoportal Municipal que permite aceder a um conjunto de serviços de dados geográficos e outras funcionalidades por eles suportadas, designadamente:

- Visualização de dados (Roteiro municipal)

- Emissão de plantas de localização 
- Consulta de Instrumentos de Gestão Territorial - IGT (Plano Diretor Municipal, Planos de Urbanização e Planos de Pormenor)

- Visualização de fotografia aérea

- Roteiro Escolar

- Reorganização administrativa

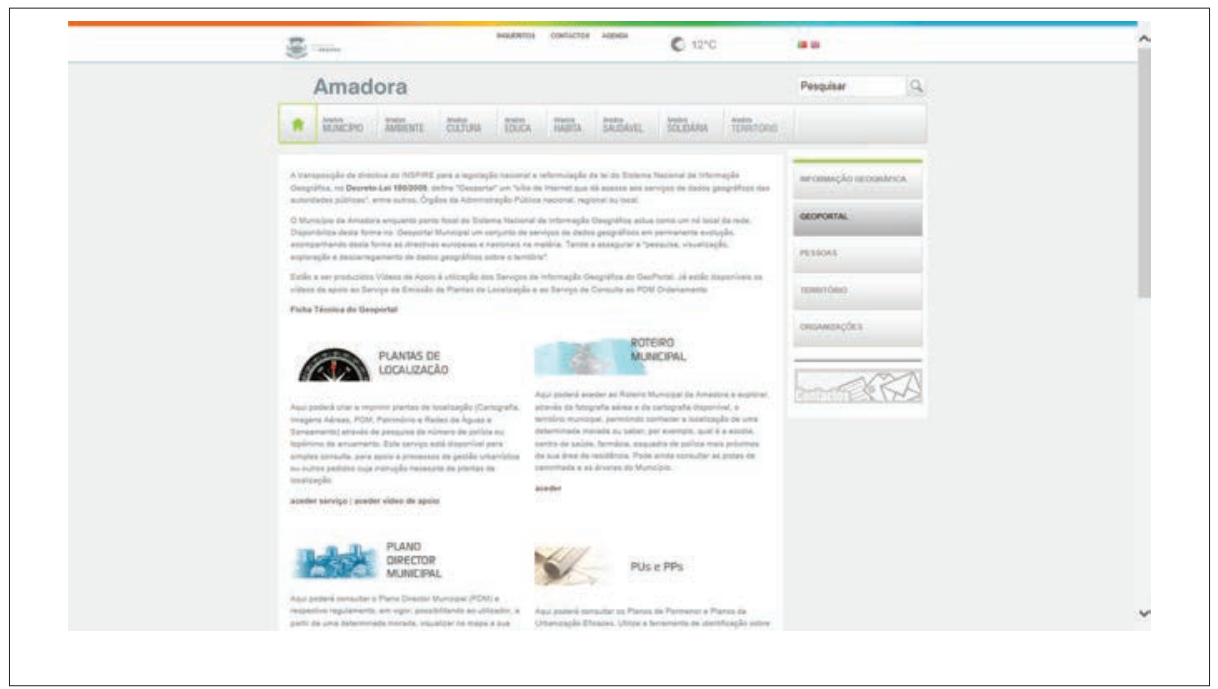

Figura 3 - Geoportal da Amadora

Este conjunto de serviços oferece aos utilizadores, amplas possibilidades de interagir com os serviços do município, explorar os dados sobre o território, embora não permita efectuar o seu descarregamento. Por exemplo, a aplicação de plantas de localização permite cruzar a localização da pretensão com os principais IGT que regulam o território no seu local e a disponibilidade de infraestruturas básicas.

Através de um conjunto de passos muito simples é possível identificar a localização da pretensão, de forma mais ou menos precisa, e posteriormente receber um PDF onde esse local se encontra sobreposto com os mapas das camadas escolhidas.

O processo efectivo de emissão de uma planta de localização inicia-se com a identificação do local da pretensão. Para o efeito é possível recorrer como base ao suporte da cartografia e ortofotocartografia e utilizar diferentes tipologias de primitivas gráficas. Desta forma garante- 
-se a possibilidade de georreferenciar com maior ou menor rigor a área da pretensão.

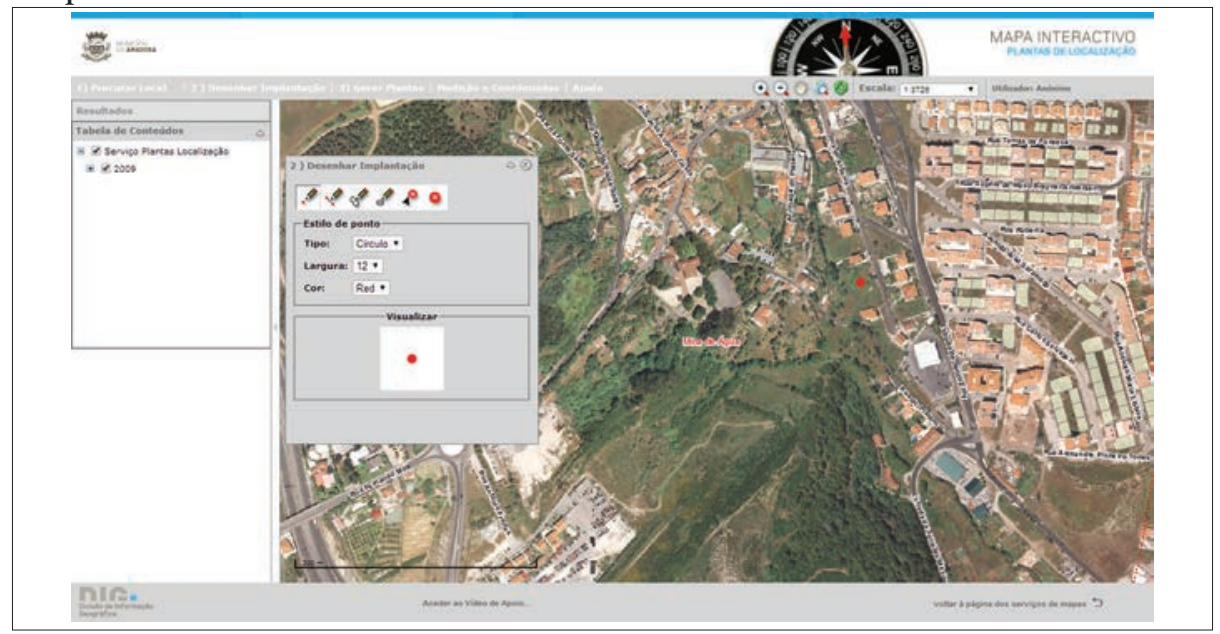

Figura 4 - Início do processo de emissão de planta de localização no Geoportal da Amadora

Os passos seguintes são os de escolher quais os IGT com que se pretende cruzar o local e o de indicar quais os documentos a descarregar da plataforma.

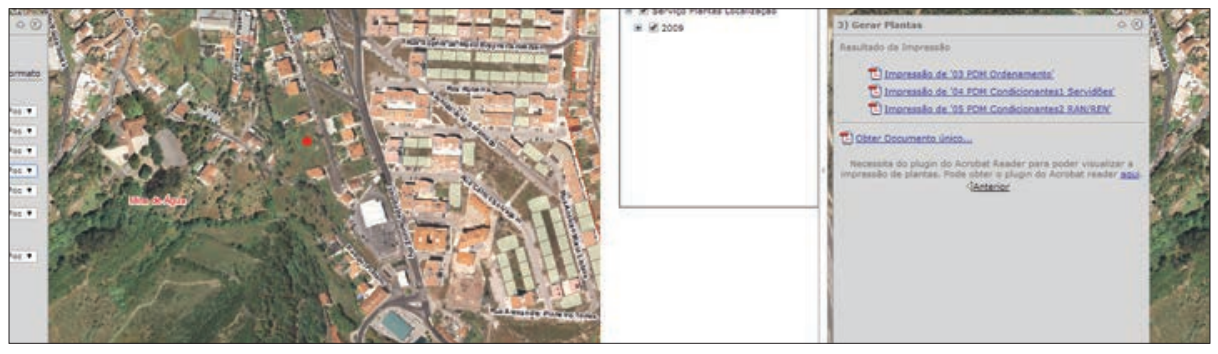

Figura 5 - Escolha dos IGT e indicação dos ficheiros a descarregar

O resultado principal do processo é a "Planta de Localização" onde a pretensão se encontra sobreposta aos IGT seleccionados ou às outras camadas possíveis, designadamente a Reserva Agrícola Nacional (RAN) e Reserva Ecológica Nacional (REN), Condicionantes e Servidões, património e também redes de água e saneamento. Esta planta permite assim efectuar a identificação prévia dos potenciais conflitos entre a pretensão 
e os instrumentos de regulação do território e aferir da existência de suporte pelas redes de infraestruturas básicas.

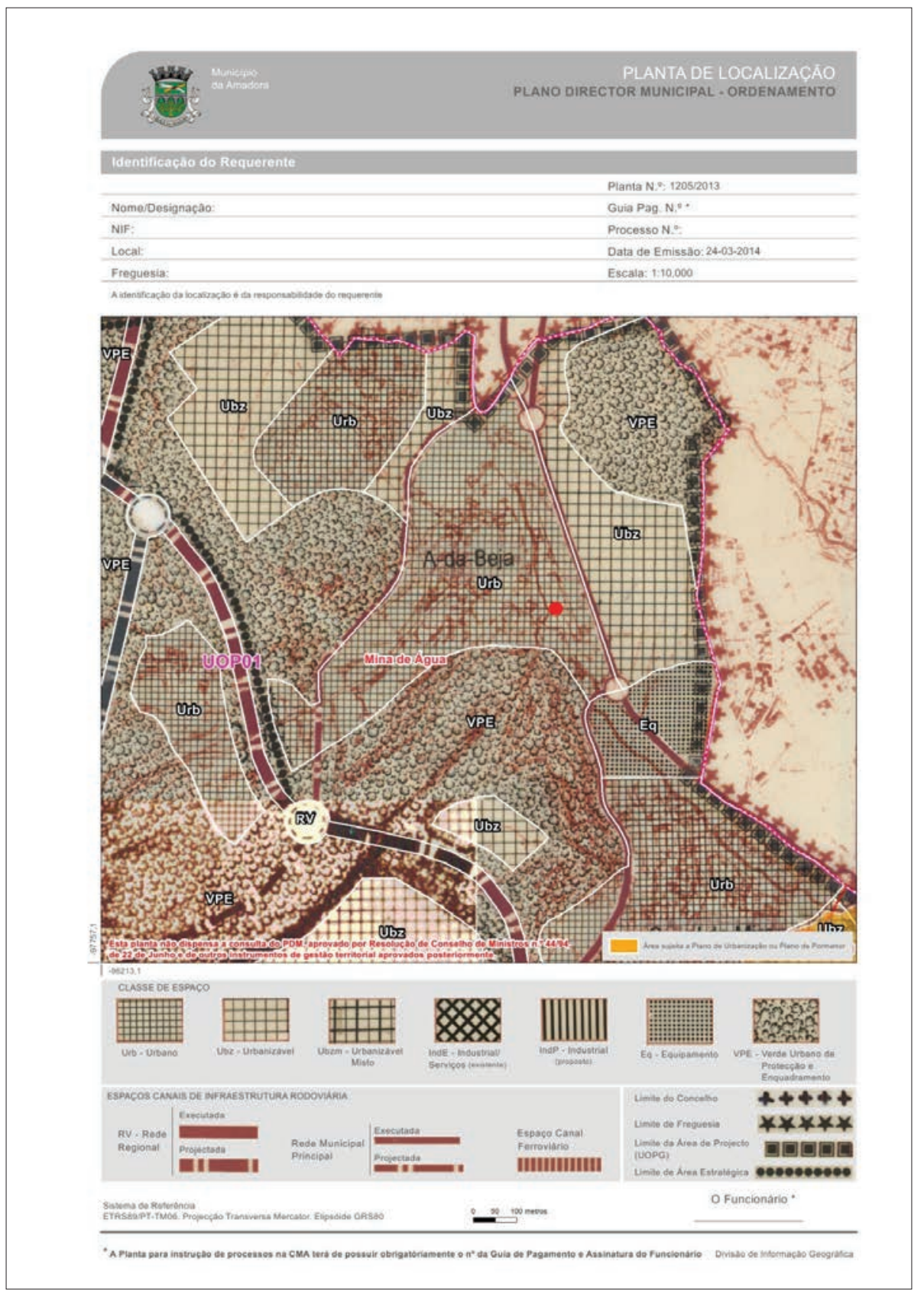

Figura 6 - Exemplo de Planta de Localização sobreposta ao PDM da Amadora 
Para dinamizar a utilização do geoportal e apoiar os seus utilizadores estão a ser produzidos vídeos que explicam o funcionamento dos serviços disponibilizados. Já estão disponíveis os vídeos de apoio ao Serviço de Emissão de Plantas de Localização e ao Serviço de Consulta ao Plano Diretor Municipal.

No domínio da exploração de novas metodologias para a aquisição expedita de dados geográficos, destaca-se um ensaio realizado com aeronave não tripulada (UAV/VANT). Este projecto incidiu sobre uma área restrita de um bairro, mas permitiu comprovar a fiabilidade e a agilidade do processo de recolha de dados relevantes para a execução de bases de suporte à gestão urbanísticas e às intervenções no território (REBELO et al, 2013).

\section{RESULTADOS E DISCUSSÕES}

Joinville e a Amadora, embora separados por um oceano, são dois municípios com uma realidade com vários pontos de aproximação e com intervenções similares no processo de recuperação de áreas degradadas através de processos de realojamento, para os quais muito contribuiu a informação geográfica existente nos respectivos SIG.

Ambos os municípios desde cedo compreenderam e apostaram no desenvolvimento dos seus SIG e criaram boas aplicações para visualização de dados, destacando-se ainda a possibilidade de descarregamento de coberturas aerofotogramétricas oferecida pelo SIMGeo Downloads.

Mas a grande vantagem do município de Joinville relativamente ao da Amadora reside no significativo avanço no que se refere à existência e exploração de dados cadastrais relativos à propriedade. Esta situação resulta do fato dos municípios no Brasil terem atribuída a competência de gestão do cadastro urbano e a possibilidade de efectuarem o mesmo quanto ao rural se assim o desejarem.

Com efeito, a informação cadastral é um pilar fundamental de uma boa prática de gestão territorial. Nenhum outro órgão público o sabe e defende melhor do que os municípios. Existindo neles capacidade técnica e tecnológica, não há qualquer razão lógica que obste a que os municípios 
efetuem a produção e gestão dos dados cadastrais, como muito bem o demonstra o caso de Joinville.

Por outro lado o município da Amadora tem um avanço significativo na componente de serviços baseados no SIG municipal e abertos ao exterior, seja por camadas de serviços integradas no Geoportal, seja pela implementação dos princípios da Diretiva INSPIRE e correspondente criação de webservices. Esta situação é típica do contexto europeu onde a aposta na infraestruturas e interoperabilidade de dados espaciais tem ganho uma forte preponderância aos mais diferentes níveis de intervenção dos órgãos públicos.

Com efeito, a Diretiva INSPIRE - Infrastructure for Spatial Information in the European Community (Directiva n. ${ }^{\circ}$ 2007/2/CE, de 14 de Março) veio estabelecer um novo paradigma de articulação de dados geográficos com origens distintas (geográfica, conceitual e semântica). Estabelece vários princípios e regras que orientam a produção (modelos de dados e normas técnicas) e disponibilização (políticas de acesso e requisitos funcionais) dos conjuntos e serviços de dados geográficos das autoridades públicas dos estados-membros. Também neste domínio o Brasil está a dar os seus passos com a dinamização da INDE que foi lançada em 2008.

Em ambos os casos verifica-se que há um importante passo que ainda pode ser dado no sentido de incorporar a participação ativa dos cidadãos através dos respetivos geoportais, seguindo os princípios da Volunteered Geographic Information (GOODCHILD, 2007) que hoje estão cada vez mais a ser adotados como forma de as administrações captarem dados do terreno.

São já vários os exemplos onde isso acontece no âmbito da intervenção municipal. A título de exemplo refira-se o caso do municípios de Águeda (Portugal) ou mesmo o projeto de âmbito nacional em Portugal "A minha rua" disponibilizado pelo Portal do Cidadão (http://www.portaldocidadao. $\mathrm{pt} /$ portal/aminharua).

\section{CONCLUSÕES}

A análise e discussão efectuada, tendo por base dois casos de estu- 
do, colocou em evidência alguns elementos estruturantes que se podem considerar como fundamentais para uma boa prática de implementação e gestão de SIG municipais e das suas aplicações em contextos de ordenamento e gestão do território.

Há alguns elementos que extravasam a perspetiva tecnológica e que são igualmente fundamentais:

- a existência de um enquadramento legal de suporte às atividades de ordenamento e gestão urbanística, bem como instrumentos de regulação do uso e ocupação do solo;

- o suporte de mecanismos de financiamento externo para as intervenções de recuperação/reordenamento em áreas ocupadas por população sem recursos económicos próprios auto-suficientes para suportar a reconversão das mesmas;

- A sensibilidade e aposta dos executivos municipais nos SIG com a sua visibilidade expressa nas páginas iniciais dos portais municipais.

Já no plano técnico e tecnológico fica demonstrada:

- a imprescindibilidade do cadastro como elemento de suporte à actividade quotidiana municipal e elemento integradores das várias componentes operativas. Só assim se consegue um constante domínio sobre a realidade do território em tempo real e com capacidade de produzir indicadores de gestão de suporte à decisão confiáveis;

- que a utilização das TIG é a única forma de fazer o acompanhamento e gestão efectivo da realidade e que estas permitem a interligação dos vários setores dos serviços municipais;

- a importância da interoperabilidade e dos princípios das infraestruturas de dados espaciais para articular os serviços internos e, sobretudo, fazê-lo com entidades exteriores com interesses no dados municipais.

Viu-se também que há a possibilidade de aplicar novos meios expeditos e menos onerosos de aquisição de dados (UAV/VANT) como uma mais-valia face às metodologias tradicionais. Com efeito a utilização de veículos não tripulados permite desenvolver acções expeditas de coleta 
de dados confiáveis.

A maior lacuna observada em ambos os casos foi a da não incorporação da possibilidade da participação cívica ativa poder ser efetuada de forma direta através dos respetivos geoportais municipais. Efetivamente, o cidadão pode e deve ser hoje um elemento ativo na produção de dados integráveis nos SIG municipais, contribuindo para uma melhor monitorização do território nas suas múltiplas perspetivas.

A experiência destes dois municípios, de dois países diferentes, com realidades distintas, revela que, estruturalmente, as abordagens seguidas foram semelhantes e que o papel dos SIG foi crucial para o seu sucesso. É certo que ambos os municípios poderão não corresponder à realidade dos restantes 5569 municípios brasileiros e dos 307 portugueses, todavia não deixam de ser duas excelentes referências pela visão, esforço e trabalho desenvolvido. Nesse sentido, é grande o potencial de aplicação destas experiências, sempre com o necessário ajustamento, a outras realidades para além de Portugal e Brasil, designadamente no espaço lusófono onde a identidade cultural é maior.

\section{BIBLIOGRAFIA}

CÂMARA MUNICIPAL DA AMADORA (2007) - Relatório do Estado do Ordenamento do Território. Câmara Municipal da Amadora, Amadora, 195p.

CARDOSO, João Francisco (2011) - Modelo de dados geográfico para a gestão do território à escala municipal. FCSH, Universidade Nova de Lisboa, Lisboa, $117 \mathrm{p}$.

CESIS (2004) - Diagnóstico Social do Concelho da Amadora. Conselho Local de Acção Social, Amadora, 211p.

GOODCHILD, Michael F. (2007) - "Citizens as sensors: the world of volunteered geography”. GeoJournal, 69 (4), Springer. 211-221.

JULIÃO, Rui Pedro et al. (2009) - Guia metodológico para a produção de cartografia municipal de risco e para a criação de Sistemas de informação geográfica (SIG) de base municipal, ANPC, Lisboa, 91p.

MARINGONI, Roberto (1927) - "O destino dos negros após a Abolição”. Para Todos, n. ${ }^{\circ}$ 458. Desafios do Desenvolvimento. IPEA. Rio de Janeiro (Brasil). Disponível online no endereço url: http://www.ipea.gov.br/desafios/index. php?option $=$ com_content $\&$ id $=2673 \% 3$ Acatid $\% 3$ D28\&Itemid=23 (acedido em 
20 de março, 2014).

PINTO, Cláudia (2011) - Cartografia 1:10000: proposta de modelo de actualização cartográfica. O caso do município do Seixal. ISEGI, Universidade Nova de Lisboa, Lisboa, 80p.

RAPOSO, Isabel \& VALENTE, Ana (2010) - "Diálogo social ou dever de reconversão? As Áreas Urbanas de Génese Ilegal (AUGI) na Área Metropolitana de Lisboa”. Revista Crítica de Ciências Sociais, n. ${ }^{\circ}$ 91, 221-235.

REBELHO, Carla et al. (2013) - "Utilização de dados UAV para o desenvolvimento de uma metodologia de mapeamento dasimétrico de alta precisão” in CORREIA, Teresa et al (eds.): IX Congresso da Geografia Portuguesa Geografia: Espaço, Natureza, Sociedade e Ciência, Associação Portuguesa de Geógrafos, Lisboa, 118-125.

SILVA, João Carlos (2010) - Migração para BD's de alta precisão e conversão em ETRS89 associadas à implementação da IDE de segunda geração do Município da Amadora. ESRI EUE 2010, ESRI-Portugal, Lisboa, 11 p.

UN-HABITAT (2012) - State of the world's cities 2012/2013. Prosperity of Cities. UN-HABITAT, Nairobi (Quénia), 149 p. 
Série Documentos

Imprensa da Universidade de Coimbra

Coimbra University Press

2015

- U M

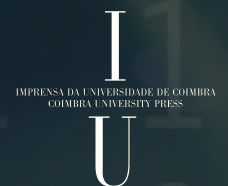

